\title{
Actual Problems of Development of the System of Higher Education of the Russian Federation: The Institutional Aspects
}

\author{
Vladimir V. Chaschin ${ }^{1}$ \\ ${ }^{1}$ Ural Institute of the Stock Market, Ekaterinburg, Russia \\ Correspondence: Vladimir V. Chaschin, Ural institute of the stock market, Siberian Route 35, 620032, \\ Ekaterinburg, Russia. Tel: 8-343-254-6238. E-mail: rector@uifr.ru
}

Received: September 20, 2014

Accepted: October 15, 2014 Online Published: November 25, 2014

doi:10.5539/ass.v10n23p244

URL: http://dx.doi.org/10.5539/ass.v10n23p244

\begin{abstract}
The system of higher education in Russia is experiencing a period of significant institutional changes related to the desire of the state to ensure availability of the benefits of higher education, high quality of services of higher education, reliability of signals of higher education in the labour market. At the same time, the tool-kit, selected by the regulator - tightening surveillance and monitoring of activity of universities - does not allow to achieve effective institutional balance. Analysis of the situation in Russia in the field of higher education, especially in the institutional aspects as well as the conceptual definition of strategic approaches to increase the effectiveness of higher education in Russia this article is devoted to.
\end{abstract}

Keywords: higher education, signals, general welfare, labour market, economic opportunism

\section{Introduction}

During the last few years (2009-2014) the Russian state has implemented a series of institutional reforms, which have dramatically changed the situation in the field of higher education.

First of all, we are discussing, of course, introduction of the Unified State Examination (USE) in 2009, which is a centralized final state attestation of high school graduates and university entrance tests simultaneously. Besides that, the conditions of supervision (compliance with licensing requirements and legislation in the field of education) and certification of institutions (state accreditation, monitoring effectiveness of the institutions) were significantly transformed and tightened. An intensive implementation of a large-scale program of improvement of practice-orientation of higher education and monitoring effectiveness of university activity in the labour market has begun. The institutional pointe of the process was represented by the Federal Law № 273-FZ dated 26.12.2012, 'On Education in the Russian Federation', which recognized the new rights and responsibilities of universities and procedure for surveillance and monitoring. These institutional novels significantly influenced both the industry situation as a whole, and the interior of the activity of Russian universities.

\section{Method}

The approach widespread today treats the higher education market as a servicing unit of the labour market, or a kind of market of production factor of production, respectively, all principles microanalysis are recognized true: in particular, overproduction in the market of higher education in itself reduces the price of a highly skilled workforce in the labour market, and decrease of quality of output of the higher education market aggravates this process, negatively affect both the field of higher education and the economy in general. And if for usual markets the mentioned above is, to some extent, a normal cyclical process of adaptation, in relation to such a significant for the society area as higher education such a process is recognized as impermissible.

At the same time - let us emphasize once again - the fight for accuracy of the standard signals presented to the labour market does not just solve the problem, but stimulates development of opportunistic trends in the field of higher education. At that, the typical qualification of graduates itself has a clear idea: reduction of transaction costs of potential employers, who in the absence of other institutional arrangements (shops, class apprenticeship system) would have to develop a system of verification of characteristics of private workers of all specialties such systems (recommendations and others) are actually already in use, but, of course, mostly as an extra.

We start from the important distinction, defined by the regulator of Russian higher education themselves: activity of the university is education and qualification. Behind this there is an implicit division of teaching for education as 
a process and education as a result of the educational process and education as socioeconomic identification (qualification, signaling).

Accordingly, from the point of view of market activity of higher education services actually include two distinct, though technologically intertwined services: education itself and skills. It has already been mentioned above that precisely such a feature of higher education determines two strategies of behavior of universities: concentration either on qualification (on the condition of standard qualifying signal) or on education directly (which requires formation of a non-standard signal system).

(Incidentally, we note again that the bilateral nature of the services of higher education determines also the way of fight of the regulator with opportunistic behavior of universities: to obstruct the opportunity of clear signal activity, i.e., simple assignment of qualification to a graduate - this process has a distinct evolutionary nature, where stimuli and responses depend on interdependence of technological and institutional steps of agents).

However, the described structure of services in the market of higher education means that the contract university-student' generates positive externalities towards potential employers (saving on transaction costs). Besides that, the sphere of higher education is a source of positive externalities for the labour market in whole (taken from the demand side), because it creates a reserve concerning universal highly skilled workforce whose training has no purpose and use of which is always in the sphere of possibility, and also forms additional qualities of an employee, which are not directly related to the matter of professional contracts.

Have conditionally distributed the mentioned external effects between the participants of the contract on the market of higher education, we find that, on the one hand, the volume of university activity is less than effective, on the other hand, the number of trained students can be considered less effective. Precisely the presence of positive externalities determines the opportunities of opportunistic activity within the framework of the contract 'university-student' (production of these external effects is partly imposed and guaranteed by the Russian state). Let us investigate this circumstance in more detail, using the well-known method of parametric matching of balance states of two areas of market activity (in this case we are talking about the version of information balance in the markets represented in the geometric form).

Thus, Figure 1 shows the balance state in interaction of universities and employers in view of positive externalities, appearance of which is due to qualifying activity of universities, encouraging economy of employers on transaction costs in the labour market - these externalities are responsible for the fact that the volume of university activity appears to be less effective.

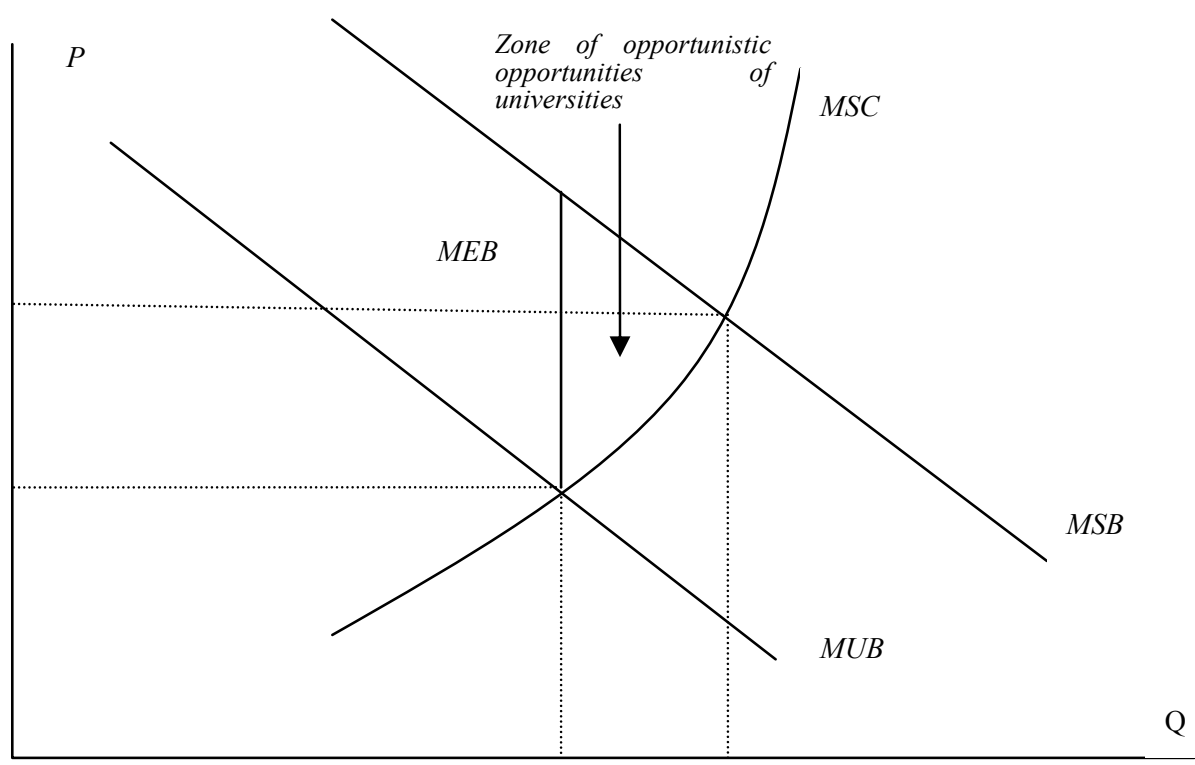

Figure 1. The relationship of universities and employers at occurrence of external effects.

$\mathrm{P}$ - cost of running educational activity, Q - volume of services rendered by the university, MEB - marginal external benefits of employers, MUB - marginal benefit of universities, MUB + MEB = MSB - the marginal benefit in general, generated by the market of higher education, MSC - marginal costs of educational activity 
It should be noted that, as the model suggests, costs of university are produced in two main directions: actual process of education and qualification process. Accordingly, university has an opportunity to choose strategy of focusing either on educational activity, or on qualifying, and in the first case, costs of students would be higher than under the conditions of implementation of the second strategy, which allows making a conclusion about possibility of increasing volume of university services in the framework of the second approach. Since in this case the actual costs of the university remain the same, the benefit of the university would be indirectly formed on the account of the employer. Thus, the second strategy corresponds to implementation of compensation of positive externalities by the university by the means of an opportunistic seizure of the employer's savings on transaction costs of personnel management.

Since here the actual parameter is accuracy of university signals, we can carry out the variation of degree of reliability of signals $\mathrm{V}$ (veracity), affecting both assessment of diplomas by employers, and cost of education for students, and, accordingly, benefit of universities and volume of university services.

The result of such variation is the possibility of building curve of balance states of the interaction (information) of universities and employers (EE - Education and Employers), shown in Figure 2. We shall recall it is the very strategy of universities, which the Russian regulator is fighting with, for whom the states of the upper part of the curve are desirable. The reliability of such actions, as it will be shown below, would not cause any doubts, if the situation in higher education were exhausted by the demonstrated circumstances.

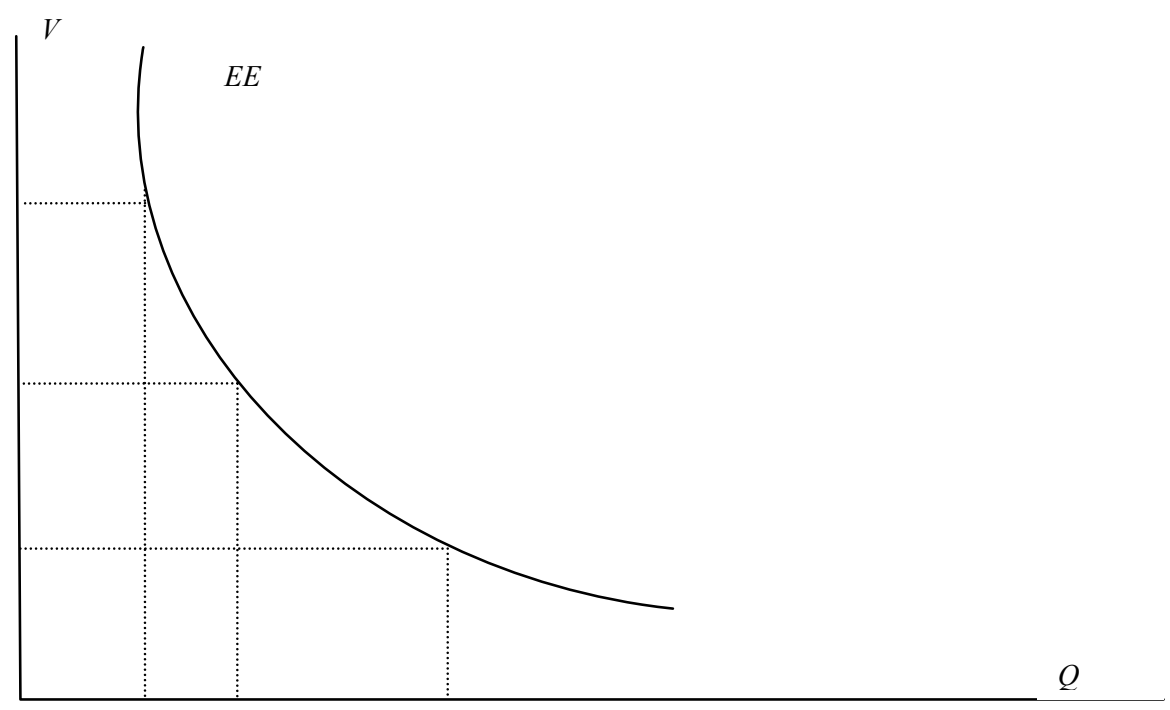

Figure 2. Dependence of volume of the services provided by university on reliability of signals, generated by universities in relation to the labour market

V - degree of reliability of the signal, Q - volume of the services, rendered by university, EE - curve of balance states of interaction between universities and employers

Turn now to analysis of interaction of students and employers, which, as it follows from Figure 3, is also characterized by positive externalities, not allowing to achieve an effective amount of students, the meaning of which is outlined above.

In this case, compensation of the externalities depends on the level of assessment of the signals of higher education by employers, that is, on magnitude of rents of higher education.

The obtained curves of balance states of interaction between universities and employers, on the one hand, and students and employers, on the other hand, allow demonstrating the general conditions of balance of these areas of the market of mass higher education, taking into account the information aspects of the processes under research and presence of external effects.

This balance is not that other, as balance between the internal characteristics and meanings of an educational service and benefits of an external service of qualification. The fact is that the market as metainstitute is based on a sort of a principle of 'epoche', retention of agents within the framework of their own interests, removal out of the borders of social benefits. At that local institutions have a formal meaning of the boundaries of market 
activity, focusing on which agents may not think specifically about the social effects of these or those realized processes. However, institutional constraints, usually, conflict with the market - especially budgetary restrictions. Opportunistic balance in this way sets in our case the inter-university technological balance distribution of costs between education as a process and education as qualification.

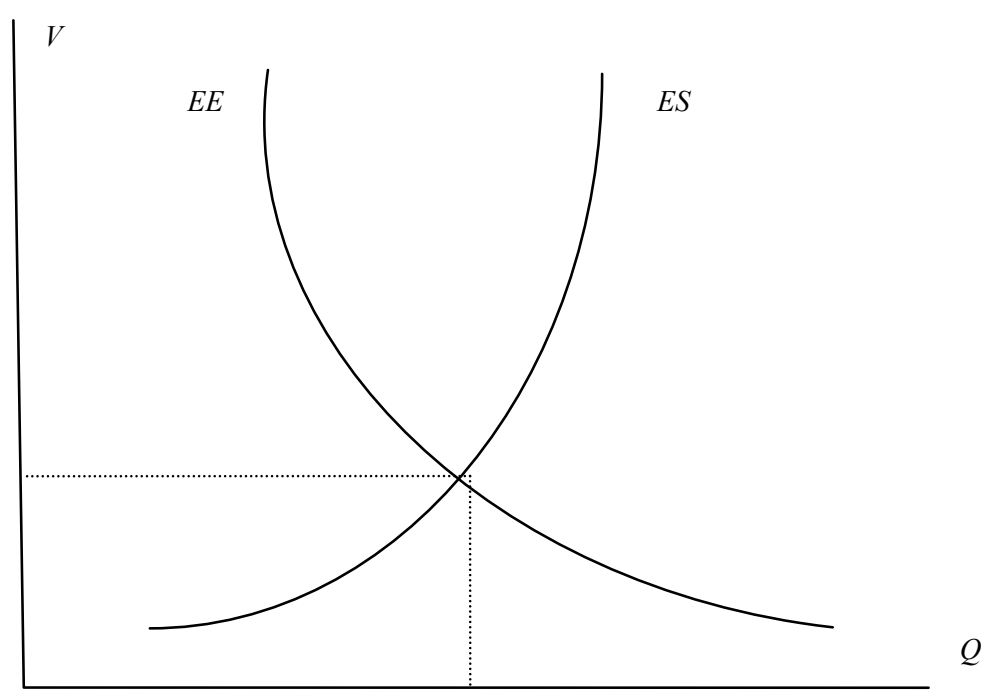

Figure 3. Balance of the areas of interaction between universities and employers and students and employers V - reliability of the signal, Q - volume of rendered educational services, EE - curve of balance states of interaction between universities and employers, ES - curve of balance states of interaction between students and employers

On the basis of the conducted analysis we will try to assess the possible sectoral effects of administrative actions from the side of the state. As it was indicated above, the purpose of the Russian regulator is the upper part of the curve EE. The controlling instance could achieve the desired with the help of significant increase of cost of purely qualifying activity that would encourage universities to tighten requirements for students and increase reliability of the signals.

However, the new value of reliability of the signals would correspond to much more potential number of students at the curve ES (as it would cause increase of rents). The field of higher education would be in a non-balanced state, and to reach balance it would be necessary to introduce non-economic measures that would ensure a shift of the curve ES to the left, which would mean the following: at a high reliability of the university signals and high rents of diploma in the labour market demand for higher education is low, that corresponds to the institutional capacities of universities.

Reality of such a policy is highly questionable; obviously, demand in this case is much less elastic towards to administrative management than the same university activity, global changes in demand nowadays are impossible. In addition, if the Russian state, regardless of costs, yet increases the level of monitoring to such extent that universities will begin to leave the market en masse (such efforts are undertaken in reality: in autumn of 2013 there were 1046 universities in the market of higher education of Russia, but by the spring of 2014 the regulator revoked 200 licenses (Popkova \& Tinyakova, 2013a), the situation in accordance with the presented model, would only get worse. The shift of the curve EE to the left will mark not only decrease of number of universities and students, but also decrease of reliability of the signals. Among the possible main reasons of this situation in the first turn there should be called the characteristics of configuration of manufacturing 'survived' universities: a large part of costs will be sent not to the educational process but to the normalization of relations with the state.

\section{Results}

As one of the main motives of the noted reforms the state declared (and continues to declare) the need of increasing competitiveness of the Russian economy, which is hindered by the numerous flaws in the current 
system of higher education. However, as it is noted in the article by R. Kapelyushnikov, analysis of the current state of higher education in the context of economic development is conducted primarily by the Western economists: for example, the recent debate of P. Krugman and G. Stiglitz on the level of investments of US students into human capital (Kapelyushnikov, 2012) is indicative in this respect. During the debate the Nobel laureates tested the hypothesis about too high percentage of people with higher education, that is, relatively low quality of human capital at its relatively high cost (current overinvestment in higher education).

R. Kapelyushnikov supports his American colleagues: in the above-mentioned study, the scientist demonstrates that employees with higher education in Russia still can pretend for economic rent in the labour market, but more often there is a discrepancy of the level of education, received by personnel, and of the position, taken by them in the organizational system (reduction of social rents of higher education) (Popkova \& Tinyakova, 2013b).

Let us emphasize that higher education in the given context is watched purely as a supplier of skilled working power for the labour market and is evaluated according to economic criteria post hoc. That is why the state remains deaf to appeals to the excellent 'internal' quality of the Russian higher education in comparison with the Western education (that is to the arguments, representing higher education of Russia as an effective social institution of general civilizational character).

Problems of modernization of the Russian economy, according to the managing instance to a large extent are linked with the actual imbalances in the labour market, where there is an excess of specialists within one qualification categories (economists, lawyers) and the lack - within other (engineers, technicians, etc. ). In addition, too big quantity of universities and effects of unfair competition related to that generate unreliability of the signals, generated by educational institutions in the labour market (low-level specialists have the same diplomas as highly qualified specialists), which stipulates both presence of problems with provision of companies with necessary staff and increase of costs of personnel management (increase of transaction costs in the field of labour relations).

Finally, according to the state, also availability of such a benefit as higher education is not alright in Russia: economic stratification of the population leads to reduction of social mobility, which is greatly encouraged by the lack of access of a significant part of citizens both to paid (the main factor of access is economic census ) and to free (organizational and social census) of high-quality higher education.

Before we transfer to the assessments of the consequeces of the described reforms, let us conduct an analysis of the institutional specifics of modern higher education, caused by complex, ambiguous nature of processes within the sphere of socio-economic relations.

\subsection{Institutional Features of the Space of Contemporary Mass Higher Education}

Education, including higher education, is a pretty conservative area of social relationships, more attracted to the sphere manufacture of public goods (although it is not such, at least in its pure form). However, under the conditions of domination of market institutions in economy (primarily in the labour market), the subjects of educational activity - first of all, institutions of higher education - have to take the relevant rules of the game and practice the elements of market method of managing, rendering paid services.

Let us use the concepts of G. Becker's theory of human capital and M. Spence's theory of market signals to analyze the market of higher education (Becker, 2003). In this sense, market behavior of higher education institutions is based on the specific structure of interactions between agents in the labour market, where the level of the expected income of working power depends on the level of formed human capital. Accordingly, higher education as a factor of improvement of the quality of human capital provides access to rent in the labour market. Namely rent of high-quality human capital is an incentive for rational agents to get higher education. At the level of signal activity we are talking about the rent of owning a higher education diploma.

In the theory of signals (M. Spence) this fact within the frameworks of analysis of information aspects of market activity is interpreted in the following way. Diploma of higher education is seen by employers as a sign (signal) distinguishing the human capital with high performance characteristics of the low-quality human capital. At the same time depending on the employer's assessment of the level of human capital and costs of higher education in the labour market there may be a separating balance, at which the employer offers and the relevant personnel take two types of revealed contracts: with a relatively low salary - for employees without higher education, with a relatively high salary - for employees with higher education.

Thereby, from this point of view, higher education diploma as a market signal is a factor of access to rent of high performing human capital, and competitiveness of the market positions of university depends on opportunities of the mentioned access, offered to applicants. In this case university can enhance attractiveness of their offer in 
two ways. Firstly, one can increase the employer's assessment regarding the quality of graduates (i.e. at other things being equal to provide increase of rent). Second, one can ceteris paribus reduce cost of access to the rent, for example, by reducing cost of (understood, in general, by Spence - as efforts of students in getting higher education) education, that is, by softening the requirements for formation of human capital in the teaching process. With appropriate state policy, as it will be shown below, both of these methods, unfortunately, can lead to unpleasant consequences for labour markets and the economy in whole.

Let us consider the second case in detail - reducing cost of access to rent a highly skilled workforce. The current situation here is similar to the model world of J. Akerlof - market with deteriorating selection (Akerlof, 1994). Indeed, if market players of the sphere of higher education keep this strategy and reduce the requirements and conditions for qualification of students, employers with increase of experience of interaction with graduates, who attended 'light' training, offer them all the less rent in each new iteration. Accordingly, also incentives for higher education decrease - the benefit of learning at that would be acquired by graduates only by those institutions that have ability to reduce specific costs of getting higher education more. In the end, the rent will decrease so much that the separating balance in the labour market would be unreachable; pretenders for vacant working places with diplomas would no longer be significantly different for employers from the usual jobseekers. Market activity of higher education institutions will be quitted.

In his program paper J. Akerlof had mentioned also recipes for fighting such a situation in the market: fair agents can make efforts on differentiating their products from opportunistic products, developing brands or issuing guarantees. Considering that important role that the sphere of higher education plays in culture and economy of any modern country, the function of a guarantor of quality of services offered in the educational market is often taken by the state, by introducing licensing and various forms of accreditation, and thereby transforming higher education from a good of experience to a good of trust. Now, both applicants and employers can save on transaction costs (including monitoring), relying on state-supported institutional system of signals: minimum acceptable level of quality of conditions of getting education is set and guaranteed by the licensing control, and accreditation indicates presence of minimum required level of quality of formed human capital (Williamson, 1996).

It should be noted that exactly this strategy was selected by the Russian State as the ideal sample, intending to optimize the system of higher education. However, reforming efforts at that are realized almost exclusively in traditional and inefficient ways.

On the one hand, the state aims at eliminating opportunistic universities using normative support of high costs of higher education, which, according to the regulator, - in the case of success - can consistently improve the quality of formed human capital, productivity of workers with higher education, rent of higher education diploma and to strengthen the incentives for getting higher education by the best potential employees.

Let us emphasize once again that in this case we are not talking about the financial side of functioning of the sphere of higher education. Finally, presence of a large sector of training, funded by the budget, in Russia to a certain extent determines the secondary importance of the factor of direct (monetary) costs of students for training. Increase of costs of higher education is realized by the state purely technologically: as it is supposed by the industrial paradigm, education is understood as a process of production of human capital, which has standard phases of management - input control, intermediate control, final quality control. These stages are made increased requirements to, moreover, presence of fairly rigid infrastructure and environmental conditions is assumed. On the other hand, the regulator demands strengthening of direct contacts with employers from universities, thereby transferring universities in the category of structural elements of the labour market. Consider some of the consequences of such events.

\subsection{Effects of Introduction of the Unified State Examination (USE) in Russia}

Thus, with introduction of USE the Russian state aimed to solve two problems: provision of access to education for 'best' and increase of the input control of university activity. In fact, on the one hand, the market nature of functioning of modern universities often stipulated the factual absence of competition while entrance, selection was made by the usual market way - by paying capacity, on the other hand - opacity of selection procedures within the frameworks of inter-university processes led to numerous abuses and cutting off of talented social outsiders from free education. However, while planning reforms, significant and perhaps unexpected by the regulator nuances remained out of the borders.

So, introduction of the USE with normative of minimum number of points, necessary for entrance to university, limitation of terms of choosing exam subjects, and later also the number of universities, where an applicant could apply, caused formation of a very tight, institutionally stipulated structure of consumer choice, where the purely 
economic factors, however, retain their value. Prestigious public universities' general having paid training departments along with budgetary places has led to the fact that applicants now prefer to choose more or less well-known educational institutions, not caring about assessment of reality of their chances to take the places of free training, as they could always count on some form of paid training in these universities.

As a result, change in the mechanism of distribution of entrants has led to that universities were divided into sector of leaders and sector of outsiders (based on the results of monitoring of effectiveness of activity of universities in 2013 about half of the higher education institutions of the country appeared to be out of the regulatory 'success'; this one more time underlines the lack of 'middle class' of Russian universities, and bundle is likely to continue to rise). Outsiders at that factually were left without flow of entrants and refocused on stock of them (pent-up demand) - here we are talking about those categories of applicants that could enter outside the frameworks of the USE, and thus make a choice relatively free and within comfortable terms: school-leavers till 2009 and graduates of secondary professional education. In addition, universities-outsiders were faced with necessity to attract applicants with low paying capacity, forcing them to set prices and conditions of training on the edge of cost-price and regulatory consistency.

Accordingly, the structure of the educational process has changed. In general, universities-outsiders have mainly switched to realization of relatively inexpensive programs of correspondence form of training and accelerated educational programs - on the background of unfavorable changes within the field of supervision and attestation. Leaders of the market in their turn found themselves in a situation of significant demand pressure; not all universities, as it might be expected, were able to resist this pressure, temptation to realize rent of new institutional conditions probably could be irresistible and result in excessive recruitment and development of non-core areas of training.

The state, have realized that the USE distributed market opportunities in a new way, has taken a number of steps aimed at reducing abuses of power by large universities: in particular, within the framework of the annual monitoring of university activity indicators minimum average grades of USE of applicants of universities were introduced - too low average grades meant new sanctions for universities.

However, this inconsistency of the regulator towards the introduced institution led to very unpleasant consequences. On the one hand, appropriateness of the USE, according to the statements of organs of state authorities, was explained by necessity of providing equal access to higher education, on the other hand, the regulator has taken opaque intradepartamental actions, being discriminatory in relation to the results of the USE. Since one of the indicators of effectiveness of universities is an average grade of CSE of applicants of an institution, because thus universities are pushed to artificial overstating of requirements at entrance, respectively, the persons, having USE results formally sufficient for entrance university, are actually deprived of the rights.

\subsection{The Effect of Changes of Conditions of Supervision and Certification Activity of Universities in Russia}

In the area of supervision and certification of universities, first of all it is necessary to note the fundamental separation of the procedures of licensing supervision by the state (since 2011 license has become perpetual, and supervision transferred to the sphere of administrative control) and state accreditation, determining ability of the institution to issue diplomas of higher education of state standard (the main, essentially, rent-forming factor, determining the system of formation and verification of signals in the sphere of education in the labour market). In addition, annual monitoring of effectiveness of activity of universities (a kind of prudential supervision by the side of industrial regulator) was introduced.

However, since regulatory structures can realize the control of activity of universities only on the basis of specific indicators, the emphasis was still placed on the study of technological signals of higher education institutions. At that the complexities of the analysis of reliability of these signals led to development of a trend at the regulator to combine expert methods with quantitative assessments. This in its turn stipulated formation of a specific internal institutional landscape of universities and institutional attractors of costs of educational institutions: focus on realization of benchmarking normatives at all costs and search for lobbying opportunities in the structure of supervising authorities.

This approach made higher education in some way similar to relationship between bank and borrower, where the long-term contract with a phased realization stipulates the necessity of strict control of credibility of a client at all stages of the transaction. Only in this case the benefit of the university from observance of all technological conditions is very indirectly - this system is aimed primarily at preventing opportunistic motives in behavior both of the university and the student: regulatory obligations, according to the controller, must generate such a flow of constant specific costs of an educational institution, at which the incentives to realization of strategies of 
influencing assessments of employers (high-quality education) become stronger than the desire to minimize costs of education (decrease of quality of education).

Though, as it is not difficult to see, and the strategy of secondary opportunism becomes attractive - within the framework of a contract of a university and supervising authority. In addition, as it was already mentioned, intensification of regulatory requirements increases the incentives of university for appropriate institutional building, and the harder is evaluation criteria, the more specific becomes the institutional landscape of educational process, where the 'peaks' correspond with standard costs, and 'valleys' - normatively not verifiable and that is why under-funded activity.

\subsection{The Effects of Realization of Programs to Improve Practice-Orientation of Activity of Russian Universities}

The state, however, rushes to ensure not only compliance with the level of development of human capital to the level of complexity of the problems occurring in the economy, but also corresponding of the structure of graduates of Russian universities to structure of these tasks. Exactly this functional, apparently, is included in gaining power regulatory requirements for direct interaction of universities and employers. Besides, in that way the state additionally encourages universities to realize the strategy of improving assessing of graduates - and, therefore, rent of higher education - by the professional community. At achievement of this effect are aimed, in particular, the requirements of federal and state educational standards of attracting a certain number of teachers-practitioners to the educational process, and the criteria for annual monitoring of employment of graduates of full-time, and the regulations on functioning of university employment services.

It is worth emphasizing that, in the opinion of the regulator, employment of almost all graduates is desirable. Higher education institutions in this case in the full sense become a part of infrastructure of the labour market the state, apparently, hopes that, at least, frictional unemployment among youth could be reduced significantly by such events. Drawing an analogy, we can say that emission of institutions of higher education in the labour market under such conditions should be entirely realized by guaranteed private subscription, and other companies may get graduates only in the secondary labour market.

Though, on the one hand, such a position is obviously controversial: with the help of a centralized system of accreditation the state creates warranties of standard of universal benefit, while encouraging universities to actively market activity, that is, to creation of a unique offer and strategies of promoting this good. On the other hand, the suggested principle of interaction between universities and employers (provision of a high level of assessment of graduates in the labour market, creation of high reputation of universities, guaranteed employment) is not so harmless.

The fact is that the impact on assessment of employers can be done in two ways: first, within the frameworks of realization of mass marketing, and secondly, while carrying out vertical integration with an enterprise or a group of enterprises. The first way cannot be available to all universities (differentiation rent is inevitable here, that with regard of the effect of scaling leads us again to the starting point of the problem), the second way enhances specificity of assets of the transaction, which in this case means the following: trajectories of realization of educational process of university are put in quite narrow corridor, stipulated by economic-technological features of counterparty. This to a large extent disavows the idea of higher education, where the main thing is not development of specific local (even the most advanced) technologies, but understanding of current trends within the professional field, high professional adaptability and mobility of graduates.

As an example, we can quote the system of higher economic education in Russia, criticized by the Russian government for the excessive number of graduates. Of course, within the system of planned economy, with clear differentiation of organization-functional corporate roles the necessary number of specialists in the field of economy could be predicted, but within the framework of market relations, involving, primarily, development of entrepreneurship, namely higher economic education can serve as a foundation for sustainable development of small and medium business (taking up to $50 \%$ of the US GDP and only $20 \%$ - of Russia's GDP), which is one of the alternatives of resource model of growth. And here at determination of the required volume of university services it is appropriate, apparently, to be guided by market principles.

\subsection{The Expected General Consequences of Reforms, Options and Prospects of Development of the System of Higher Education in Russia}

However that may be, actions taken by the regulator may lead to a real reduction of supply in the market of services of higher education in Russia. However - in accordance with the ideas of A. Sen, - the progress of society is related not to the quality of current consumption, but with the opportunities (or, literally, - access by North, Vayngast and Wallace), that a person possess (North et al., 2009; Sen, 2004). Losses from limiting access 
to higher education (alternartive costs) are, of course, difficult to estimate, but it's not impossible that they will exceed the benefits of a general increase in the level of training graduates.

This hypothesis is more likely in the present conditions, when higher education in Russia is increasingly become to be taken as an obligatory attribute of modern humans. We illustrate this in the following way: the rent of the secondary education in a relative sense is much higher than the rent of higher education in the labour market, but now in Russia anyone would not think to conduct an alternative analysis while selecting of trajectories of social development at the stage of finishing of pre-school education by a child. Secondary education is a truly universal, institutionally rooted as such, and attempts to increase the rent of certification or to improve the quality of a school-leaver by limiting access to this level of education can seriously affect the social consensus.

Thereby, within the field of higher education there is an uneasy task for realization of the relatively effective balance in the interfacing markets under the conditions of non-worsening of achieving the position of agents (in terms of available opportunitites) by this time. And here, probably in the first place it is worth to pay attention to the contrast contradiction between understanding of higher education as rendering of services and production paradigm, formed in fact by the state and practiced in the universities. Of course, one can try to combine these approaches, but in the result we get an exotic concept: university, serving as an expert, as if render services for producing human capital from students that can qualify for the rent in the labour market. At that the 'raw material' of the production process - students - in fact, always remains passive. At best, here it is possible to talk about a peculiar paternalism: professionals of the sphere of education better know what is useful for students, and that is dangerous - the last have only to obey the will of benefactors.

From the point of view of modern microeconomics, we are talking about specificity of a benefit, formed within higher education: to train a professional for 'the needs of an enterprise' (popular expression used at all levels of the Russian authority) - means, first, to generate a contract with a highly specific asset of an employee (and consequently, to put the employee in knowingly hard terms), and secondly, to reduce the innovation potential of higher education (forming of organization-technological complex of an employee), third, to destroy meaning of now existing system of universal qualification signals (since any particular company prefers more precise local system of verification of specific candidates).

In other words, university, in addition to orientation at the labour market, should concentrate on providing an independent service with its own meanings. And if the university will prefer to represent close interaction with potential employers to applicants as such - this is the right and the way of the institution to ensure their competitiveness, which, however, does not cancel possibility of existence of other goals of higher education. From the 'source of manpower' and attachment of the labour market, higher education should transform into a zone of increase of social welfare, zone of consumption (creation of human capital is unique and occurs exactly during the process of consumption), the results of which can be used in different spheres of social life.

Against this position, however, one can nominate two already mentioned above simple but so strong objections that it is rational to consider them once again. The first objection is one of the consequences of ensuing abroad and supported in the Russian discussion on the economy of modern higher education: lack of a direct link of the sphere of professional education with the labour market can lead to excessive investment in higher education, which will cause reduction of the general welfare. At that the thesis about decrease of welfare can be proved in two ways. On the one hand, the excessive investment in higher education, understood as a kind of industrial sector of the labour market as a market of production factor, will lead to the fact that a highly skilled workforce will be offered at a price higher than what employers are willing to pay. Allocative inefficiency will determine the relative decline of social wealth.

On the other hand, if distribution of information on the labour market is imperfect and potential employees as bounded rationality subjects have formed the wrong expectations about future rents of higher education, excessive investment in higher education will lead to a relative depletion of these agents. (Note that in the first case the meaning of the possible managing efforts is to ensure market efficiency - that means, that we are probably talking about the effects of market failure, in the second case we are faced with the already mentioned paternalism - correction of non-optimal behavior of individuals).

The second objection can be derived from the features of the world of J. Akerlof. Indeed, if the market of used cars managed to organize the qualifying authority allotting 'plums' with the mark of quality, but the sellers of 'lemons' in this case would be able to develop institutional technologies, allowing providing variability of the meanings of this sign at immutability of its form, the situation after receiving new experience by the buyer would be no different from the old one: the average price of the purchase would fall, that, first of all, would be 
detrimental to the best and fair, reducing the incentives for their participation in economic processes, and shared losses would be added by inefficient costs on verification software (Popkova et . al., 2013a).

It should be noted that the noted problem is valid for almost all modern countries, which built the system of mass higher education. Procedures of verification, ensuring the quality of education, in one form or another are commonly used, generating the similar difficulties. For example, in the reports of the association ENQA reliable qualifying European instance - it is often possible to find reports about abuses of universities associated with expert procedures (Motova, 2014).

Failure of the system of standardized signals leads to self-differentiation of the markets of higher education, stipulating appearance of specialized segments: elite education (Ivy League, universities of excellence class), research universities and institutions of mass servicing. Technological differentiation is also carried out: stage of mass higher education - Bachelor studies, advanced training - Master studies, research degree (post-grade courses, etc.) are distinguished. Undoubtedly, thereby, the search of compromise within the framework of the dual 'distribution - allocation', that is, 'effective - socially acceptable' (question is explicated, for example, by M. Allais, whose one of the main theses is the statement of a purely technical, formal indifference of the balance to the methods of achieving it (Allais, 1998) is carried out. In Russia this search, unfortunately, ended till nowadays with the birth of a strange hybrid - higher education, located between Humboldt's and Napoleon's models.

Search for new conceptual-instrumental capabilities, not contradicting any modern social or current economic conditions is needed; the analysis in this case has to be carried out both at the microeconomic level and at the level of a separate institution.

\section{Discussion}

On the basis of the study we can propose the following alternatives in development of the institutional aspects of the Russian higher education. In this situation, the easiest way would be to declare about necessity of dispensation of excessive state intervention. However, the institutional revolution in this case is dangerous and is not appropriate. As it was noted above, in modern society it is important to provide access of individuals to the opportunities, but universal access at the same time can destroy these opportunities. It is very important to encourage social mobility (higher education plays a crucial role here), but uncontrolled providing of opportunities is capable to overflow channels of social mobility and significantly reduce their effectiveness. The matter of mass higher education, thereby, is one of the most complex issues of the present. This problem is a dialectic problem, and at a particular level of realization it is shown in conflict and contradictory processes, including in reduction of the immediate impact of higher education. Nevertheless, higher education refers to the basic fields of social and economic interaction, and selection of trajectories of its development affects the public welfare, not only through direct effects in the labour market (Popkova et. Al., 2013b).

Client orientation in activity of universities in this context would mean big individuality of educational trajectories, possibility of changing specialization or place of training, in combination with pluralism within the sphere of qualification will allow to satisfy the diverse needs of a significant part of clients of universities without damage for reliability of the formed signals. Of course, with increase of opportunities of university activity additional opportunistic opportunities would appear, but distinction of opportunism in highly standardized field of opportunism in the pluralistic institutional environment is constituted in that the latter both requires less efforts and produces less inefficiency: the thinner are institutional gaps between the alternatives, the less opportunism is different from the norm.

An important point is the fact that the proposed does not require additional institutional work. The Education Law, acting in Russia already contains all necessary elements: possibility of networking, concept of public accreditation of individual educational trajectory, academic mobility and cumulative (multiqualificational) principle of higher education. It is up to the correct understanding and realization of these concepts.

Modern higher education can be interpreted also as a social institution and as a market phenomenon, although, apparently, here we are talking about two ideal types of realization of the system of higher education, not excluding possibility of intermediate states. Higher education, understood as a public good generates problems of determining fair access, eliminating different variations of 'tragedy of the commons', problems of combination with market institutions (first of all, with the labour market), problems of correspondence with the dynamic aspects of the modern economy.

Higher education as a market phenomenon stipulates necessity of solving of the problem of compensation of external effects and explication of the essence of the rendered services (education and qualification), which the 
institutional support of the higher education market, adequacy of the signals, of intensity of opportunism and efficiency of higher education in general depends on.

The said depends a lot on what type of role in the institutional and market sphere of higher education is taken by the state. Unfortunately, we must admit that nowadays Russian managing instance principally does not distinguish higher education as a market and as an institution. Partly, such unproductive position is connected with the historically developed situation in which the Russian state is both the customer and the consumer, and the regulator of the sphere of higher education. Accordingly, the choice mode of action by the state remains uncertain: determination of the rules of the game, with understanding of higher education as a market phenomenon or a specific management at perception of education as an institution.

The last position, moreover, has important nuances: education can be understood either as an institution (but not the market!) of training professional labour, or in a broader sense - as an institution, providing socialization, as well as civilizational, cultural succession of generations and development of the country. And the same strict criteria for selection of applicants, developed forms of control are needed if society takes the system of higher education only as an institution - source of manpower for the national economy. Meanwhile, we can talk about higher education and in another sense.

Efficiency, understood as a direct return of higher education in the sphere of national economy, today, cannot be considered the only measure of university activity. Development of higher education is related to solving of important problems of public welfare, where the main principle is the effective non-discriminatory distribution of capabilities.

\section{References}

Akerlof, G. (1994). Market "lemons": Quality uncertainty and the market mechanism. THESIS, 5.

Allais, M. (1998). Terms efficiency in the economy. Moscow.

Becker, G. (2003). Human behavior: An economic approach. Selected Papers on Economic Theory. Moscow, Higher School of Economics.

Kapelyushnikov, R. (2012). Demand and supply of highly skilled labor force in Russia who ran faster? Problems of Economics, 2(3).

Motova, G. (2014). Accreditation as a tool to improve the quality of education. Accreditation in Education. Retrieved from http://www.akvobr.ru/akkreditacia_kak_instrument.html;

North, D., Wallis, J., \& Weingast, B. (2010). Violence and social orders. Conceptual framework for the interpretation of the written history of mankind. Moscow.

Popkova, E. G., \& Tinyakova, V. I. (2013a). Dialectical Methodology of Analysis of Economic Growth. World Applied Sciences Journal, 24(4), 467-475.

Popkova, E. G., \& Tinyakova, V. I. (2013b). Drivers and Contradictions of Formation of New Quality of Economic Growth. Middle-East Journal of Scientific Research, 15(11), 1635-1640.

Popkova, E. G., Chaschin, V. V., \& Bogdanox, D. V. (2013). Implementation of the Concept of Personnel Marketing In Modern Russia. World Applied Sciences Journal, 22(3), 389-395.

Popkova, E. G., Shachovskaya, L. S., \& Romanova, M. K. (2013). Bases of Transition of the Territory to Sustainable Development: Modern City. World Applied Sciences Journal, 23(11), 1499-1507.

Sen, A. (2004). Development as Freedom. Moscow, New Publishing.

Spens, M. (1973). Job Market Signaling. Quarterly Journal of Economics, 87.

Tullock, G. (2011). Public goods, redistribution and rent seeking. Moscow.

Williamson, O. (1996). Economic Institutions of Capitalism: Firms, Markets, "relational" contracting. St. Petersburg: Lenizdat, CEV Press.

\section{Copyrights}

Copyright for this article is retained by the author(s), with first publication rights granted to the journal.

This is an open-access article distributed under the terms and conditions of the Creative Commons Attribution license (http://creativecommons.org/licenses/by/3.0/). 